UCRL-ID-129887

\title{
Tunable, Diode-Pumped Solid-State Laser for Scalpel with Adjustable Penetration Depth
}

\author{
R. H. Page
}

February 10, 1998

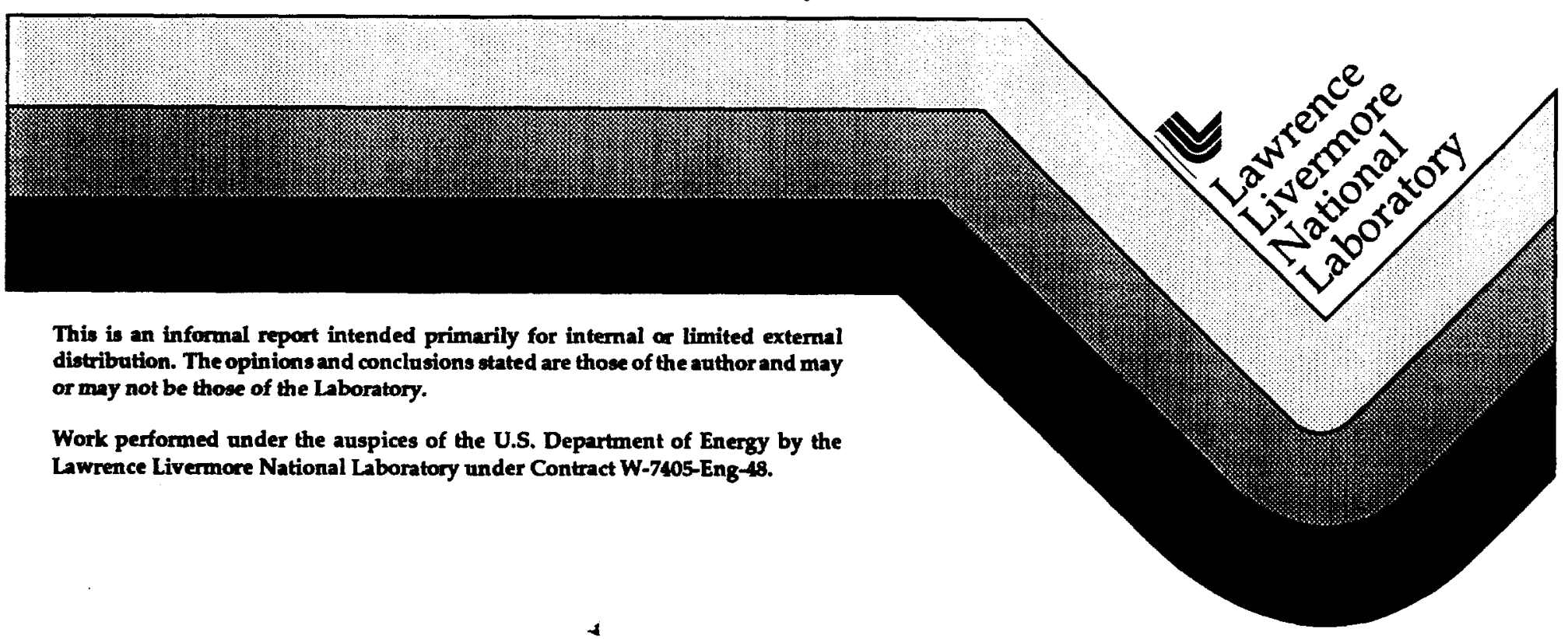




\section{DISCLAIMER}

This document was prepared as an account of work sponsored by an agency of the United States Government. Neither the United States Government nor the University of California nor any of their employees, makes any warranty, express or implied, or assumes any legal liability or responsibility for the accuracy, completeness, or usefulness of any information, apparatus, product, or process disclosed, or represents that its use would not infringe privately owned rights. Reference herein to any specific commercial product, process, or service by trade name, trademark, manufacturer, or otherwise, does not necessarily constitute or imply its endorsement, recommendation, or favoring by the United States Government or the University of California. The views and opinions of authors expressed herein do not necessarily state or reflect those of the United States Government or the University of California, and shall not be used for advertising or product endorsement purposes.

This report has been reproduced directly from the best available copy.

Available to DOE and DOE contractors from the Office of Scientific and Technical Information

P.O. Box 62, Oak Ridge, TN 37831

Prices available from (615) 576-8401, FTS 626-8401

Available to the public from the

National Technical Information Service

U.S. Department of Commerce

5285 Port Royal Rd.,

Springfield, VA 22161 
96-LW-005 final report

February 10, 1998

Tunable, Diode-Pumped Solid-State Laser for Scalpel with Adjustable Penetration Depth

\section{Ralph H. Page}

Lawrence Livermore National Laboratory

Livermore, California 94550 


\section{Introduction}

Three years ago, as part of a remote-sensing project, we discovered a new class of tunable mid-infrared (IR) transition-metal lasers: $\mathrm{Cr}^{2+}$-doped zinc chalcogenides. This is the first time that an efficient, widely-tunable, mid-IR laser operating at room temperature was produced. The broad emission linewidths of the $\mathrm{Cr}^{2+}$ dopant ions, and their strong, highly-luminescent optical transitions are reminiscent of the well-known Ti:sapphire system. Table I compares the spectroscopic properties of the Ti:sapphire and $\mathrm{ZnSe:Cr}$ systems. There is a fairly close analogy, probably due largely to the fact that both dopant ions are transition metals, and to the similarity of electronic energy level structures (evident in the $\mathrm{E} \rightarrow \mathrm{T}_{2}$ optical transition.) A key difference-aside from $3 \times$ longer transition wavelengths around $2400 \mathrm{~nm}$-is the much larger magnitude of the absorption and emission cross sections. This leads to a much smaller value of the "pump saturation intensity," making it easier to pump the laser to threshold. In principle, a $\mathrm{ZnSe}: \mathrm{Cr}$ laser could be pumped efficiently by laser diode arrays whose peak intensity is on the order of a few $\mathrm{kW} / \mathrm{cm}^{2}$. Thus we recognized the potential of creating a widelytunable, diode-pumped mid-IR laser. By virtue of the diode pumping, its efficiency would presumably be high, and use of a powerful pump array might lead to a high laser output power (i.e. several watts.)

Table I. Spectroscopic characteristics of Ti:sapphire and $\mathrm{ZnSe:Cr}{ }^{2+}$

\begin{tabular}{|c|c|c|c|}
\hline & & $\mathrm{Ti}^{3+}: \mathrm{Al}_{2} \mathrm{O}_{3}$ & $\mathrm{ZnSe}: \mathrm{Cr}^{2+}$ \\
\hline Transition & & ${ }^{2} \mathrm{E} \rightarrow{ }^{2} \mathrm{~T}_{2}$ & ${ }^{5} E \rightarrow{ }^{5} T_{2}$ \\
\hline Upper-level lifetime & $\tau_{\mathrm{em}}(\mu \mathrm{sec})$ & 3 & 9 \\
\hline Peak fluorescence wavelength & $\lambda_{\max }(\mathrm{nm})$ & 800 & 2300 \\
\hline \multirow{2}{*}{$\begin{array}{l}\text { Fluorescence } \\
\text { linewidth (RT) }\end{array}$} & $\Delta v\left(\mathrm{~cm}^{-1}\right)$ & 4300 & 1700 \\
\hline & $\Delta \lambda(\mathrm{nm})$ & 300 & 1000 \\
\hline Relative bandwidth & $\Delta \lambda \lambda_{\max }$ & 0.38 & 0.43 \\
\hline Peak pump cross- section & $\sigma_{a b s}\left(10^{-20} \mathrm{~cm}^{2}\right)$ & 6.5 & 87 \\
\hline Pump saturation intensity & $I_{\text {sat }}\left(\mathrm{kW} / \mathrm{cm}^{2}\right)$ & 2000 & 14 \\
\hline
\end{tabular}

While there are many applications for tunable IR light-remote sensing, optical countermeasures, and pollution monitoring, to name a few-we felt that medicine (surgery in particular) would benefit from the availability of an engineered $\mathrm{ZnSe}: \mathrm{Cr}^{2+}$ laser system. The reason is that wavelength tunability could add a new dimension to laser surgery. Laser energy deposition during surgery on biological tissue is largely governed by the absorption coefficient of water, which is strongly wavelength-dependent, especially in the IR region around $2000-3000 \mathrm{~nm}$. With a wavelength-tunable laser, a surgeon would be able to control both the laser power and the penetration depth. This would allow optimization of the balance between cutting and coagulation. Both delicate cutting, such as that required for corneal sculpting, and more aggressive surgical procedures would then be possible with the same system. Thus, a $\mathrm{ZnSe}: \mathrm{Cr}$ laser could potentially replace a suite of other surgical lasers, including the Er:YAG, Er:YSGG, $\mathrm{CO}_{2}$, and Nd:YAG lasers. Its light could be delivered via a silica optical fiber (or perhaps a sapphire fiber in the longest-wavelength regions,) in contrast to a $\mathrm{CO}_{2}$ laser, for which good fibers do not yet exist. 
Yet another important variable of laser energy deposition during surgery is the timescale in which the energy is delivered. Generally, surgical efficacy improves when energy is deposited much faster than it is conducted away. This is most noticeable when small regions are illuminated, since the heat has less distance to travel to be dissipated. A short-pulse (nanosecond) system could therefore work better than a microsecond-tomillisecond-pulse system. The literature on laser surgery is rife with papers comparing the relative efficacy of lasers at different wavelengths and different pulse durations.

Our LDRD project had several goals pertaining to laser development:

- Demonstrate a widely-tunable $\mathrm{ZnSe}: \mathrm{Cr}^{2+}$ laser;

- Demonstrate diode-pumped operation of a $\mathrm{ZnSe}: \mathrm{Cr}^{2+}$ laser;

- Scale the laser's output power up to several watts;

- Obtain short (tens of nsec) pulse operation.

As described in more detail below, we were partially successful in meeting these goals. Briefly, we were able to obtain laser operation over quite a large tuning range covering $\sim 2150-2800 \mathrm{~nm}$, and did achieve diode-pumped operation. In fact, the diode array developed for pumping the laser worked quite well. Unfortunately, obtaining a high output power and short-pulse operation are more challenging tasks on which we made only partial progress. However, since other research groups have taken interest in our work and taken up the study of $\mathrm{Cr}^{2+}$ lasers, progress will continue to be made, even if not at LLNL.

\section{Diode-pumped laser and semiconductor saturable absorber designs}

We considered a few different designs for diode-pumped $\mathrm{ZnSe}: \mathrm{Cr}^{2+}$ lasers. A persistent problem in laser design is the coupling of pump light from a rectangular region (the diode array) to the resonated volume in the laser. In many diode-pumped lasers, end pumping is preferred, and sophisticated beam-shaping optics (including "lens ducts") are used to provide spatial formatting of the pump light. Effective formatting to achieve high on-axis intenisites is critically dependent on the divergence of the diode light. Since we were dealing with a hitherto-uncharacterized set of long-wavelength laser diodes (see below,) we felt that end-pumping was a risky option. The diode devergence was not yet known, and lens ducts for long-wavelength light are not routinely available, and could likely be very lossy owing to OH-overtone absorption in wet fused silica. Furthermore, in end-pumped lasers a dichroic mirror is needed to transmit pump light and reflect the resonated beam, and we have not yet had experience working with such mirror coatings on $\mathrm{ZnSe}$ for the $1.8-2.5 \mu \mathrm{m}$ region.

A simpler design that allows facile coupling of light from diode-bar arrays is that of Figure 1, a side-pumped "brick" with a "TIR bounce" of the resonated beam. The diode light is focused with a cylindrical lens to a stripe, creating a ribbon-shaped gain volume in the brick. (Depending on how strongly the pump light is absorbed, the gain region may extend all the way through the crystal.) Antireflection (AR) coatings are applied to the ends of the brick, and since the resonated beam enters and exits at a small distance from the edges of the brick, diffraction losses (due to "scraping") are virtually eliminated. We used the design of Fig.1, popularized by Alcock[1] in all of our diodepumped experiments. 


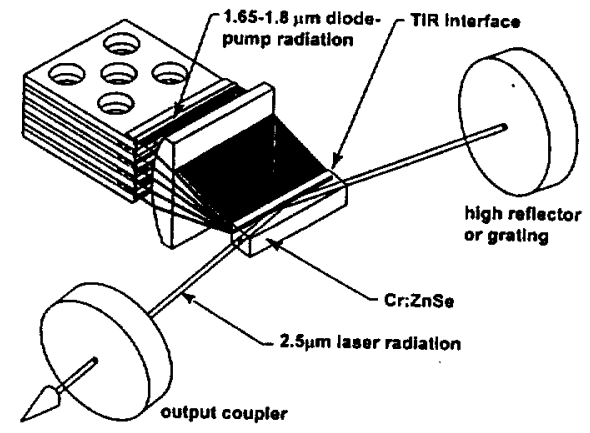

Fig. 1. Diode-side-pumped laser design, which facilitates integration of a $\mathrm{ZnSe:Cr} \mathrm{slab} \mathrm{and} \mathrm{a} \mathrm{multiple-bar} \mathrm{diode} \mathrm{array.}$

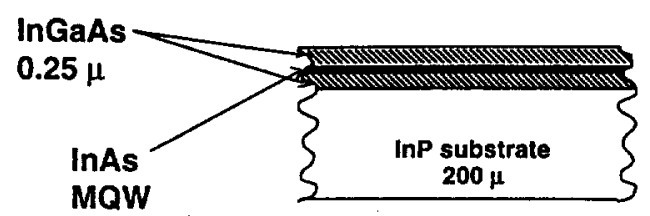

50-200 A

Fig. 2. Multiple-quantum-well (MQW) semiconductor-saturable-absorber passive Q switch.

As a passive Q-switch we had planned to employ a semiconductor saturable absorber[2] (Figure 2.) The saturable-absorber multiple quantum well (MQW) layers are sandwiched between InGaAs buffer layers, and the entire device is supported by an InP wafer. At the wavelengths of interest for the $\mathrm{ZnSe}: \mathrm{Cr}^{2+}$ laser, the InP and InGaAs layers are transparent. Low Fresnel losses could be obtained by using the wafer at the Brewster angle in the cavity. Such structures have been known for roughly a decade but have not found their way into traditional "energy-storage" solid-state lasers because the intracavity fluences have been too high, causing damage to the semiconductor. Because of a high laser cross section, the saturation fluence of the $\mathrm{Cr}^{2+}$ ion is $\sim 0.1$ joule $/ \mathrm{cm}^{2}$, roughly $1 \%$ that of Ho:YAG and other rare-earth-ion lasers, eliminating this problem. In fact, the saturable absorber's saturation intensity must be below that of the gain medium itself to allow Q-switching,[3] and the MQW saturable absorbers have $\mathrm{I}_{\text {sat }} \sim 1-10 \mathrm{~kW} / \mathrm{cm}^{2}$, comfortably below the $\mathrm{Cr}^{2+}$ saturation intensity of $\sim 20 \mathrm{~kW} / \mathrm{cm}^{2}$. Since our laser diode group was already capable of producing high-performance MQW structures, we felt that fabrication of a saturable absorber would play naturally to its strength.

\section{Experiments}

\section{A. ZnSe:Cr Crystals}

To build an efficient laser, we strove to increase the $\mathrm{Cr}^{2+}$ concentration while maintaining low loss at the laser wavelength. High doping is especially important in side-pumped lasers, which tend to have poor mode fill unless the pump light is absorbed in a shallow layer near the surface of the crystal. Although several techniques have been used to produce $\mathrm{Cr}^{2+}$-doped $\mathrm{ZnSe}$ and $\mathrm{ZnS}$ crystals, we found diffusion-doping to be a simple and effective method. Undoped blanks are placed with $\mathrm{CrSe}$ powder in an evacuated quartz ampoule, which is heated to a temperature of $800-1000 \mathrm{C}$ for a few days. The blanks can be either sintered CVD-grown material (commonly used for laser windows, lenses, etc.) or single crystals. Nowadays, single crystals are grown by the Seeded Physical Vapor Transport (SPVT) technique. Diffusion of divalent transition metal ions in zinc chalcogenides is fairly thorough; the interiors of the blanks come out rather uniformly doped. On the other hand, the exact doping mechanism is not known at this time, since $\mathrm{CrSe}$ is not expected to volatilize at the diffusion temperatures we employed. It is suspected that volatile impurities (e.g. water) within the ampoules are acting as transport agents. 
Table II. Characteristics of $\mathrm{Cr}$-doped crystals used in laser experiments

Crystal Characteristics

\begin{tabular}{|c|c|c|c|c|c|}
\hline $\mathrm{S} / \mathrm{N}$ & Origin* & $\begin{array}{l}\text { Diffusion-doping conditions/remarks } \\
\text { (CrSe unless otherwise indicated) }\end{array}$ & $\begin{array}{l}\alpha_{\text {peak }} \\
{\left[\mathrm{cm}^{-1}\right]}\end{array}$ & $\begin{array}{c}\alpha_{\text {1oss }} \\
{\left[\mathrm{cm}^{-1}\right]}\end{array}$ & FOM \\
\hline 663 & ZnSe poly & $850^{\circ} \mathrm{C} \quad 5$ days & 18. & 0.65 & 28 \\
\hline 666 & ZnSe SPVT & $900^{\circ} \mathrm{C} \quad 2$ days (FY96 DPSSL sample) & 1.86 & 0.16 & 12 \\
\hline 667 & Zns poly & $900^{\circ} \mathrm{C} \quad 3$ days & 1.35 & 0.60 & 2.3 \\
\hline 669 & ZnSe poly & $900^{\circ} \mathrm{C} 2$ days $(\mathrm{Zn}+\mathrm{CrSe}$ in ampoule) & 20. & 0.77 & 26 \\
\hline 670 & ZnSe SPVT & $925^{\circ} \mathrm{C} \quad 5$ days (Brewster-cut slabs) & 5.2 & & \\
\hline 681 & ZnSe poly & $\begin{array}{ll}900^{\circ} \mathrm{C} & 2 \text { days }(\mathrm{Zn}) / \\
900^{\circ} \mathrm{C} & 2 \text { days }(\mathrm{CrSe}) \\
\end{array}$ & 11.7 & 0.32 & 37 \\
\hline 690 & ZnSe SPVT & $900^{\circ} \mathrm{C} 14$ days (FY97 DPSSL sample) & 6.3 & 0.13 & 49 \\
\hline 694 & ZnSe SPVT & $950^{\circ} \mathrm{C} \quad 5$ days & 12.2 & 0.18 & 66 \\
\hline 697 & ZnSe SPVT & $1000^{\circ} \mathrm{C} \quad 5$ days & 8.7 & 0.16 & 56 \\
\hline 701 & ZnSe SPVT & $950^{\circ} \mathrm{C} \quad 5$ days $(\mathrm{Zn}+\mathrm{CrSe}$ in ampoule) & 4.2 & 0.22 & 19 \\
\hline 709 & ZnSe SPVT & $900^{\circ} \mathrm{C} 14$ days $(\mathrm{Zn}+\mathrm{CrSe}$ in ampoule) & 5.3 & 0.28 & 19 \\
\hline 12435 & ZnSe SPVT & As grown material & 2.0 & 0.098 & 20 \\
\hline
\end{tabular}

- poly: polycrystalline CVD-grown window material; SPVT: Seeded Physical Vapor Transport

To evaluate the doped crystals, we used a spectrophotometer to obtain an absorption spectrum, from which we obtained the $1800 \mathrm{~nm}$ pump absorption coefficient $\alpha_{\text {peak }}$. The laser loss coefficient $\alpha_{\text {loss }}$ (evaluated at $2350 \mathrm{~nm}$ ) was derived by measuring attenuation of a $\mathrm{MgF}_{2}: \mathrm{Co}^{2+}$ laser beam after it traversed a substantial thickness $(\sim 1 \mathrm{~cm})$ of material. A "figure of merit" FOM $\equiv \alpha_{\text {peak }} / \alpha_{\text {loss }}$ can be used to describe crystal quality; it is always desired to have a large FOM, and for side-pumped lasers, normally $\alpha_{\text {peak }}>10 \mathrm{~cm}^{-1}$ is appropriate. Table II shows some results for various doped crystals, including the starting material, doping conditions, pump absorption and laser loss coefficients, and figure of merit. We did achieve fairly high values for $\alpha_{\text {peak }}$ in some cases, and the FOM ranged up to 66, which is a factor of at least 3 or 4 improvement with respect to our early work. We are pleased with our ability to create useful laser material with good reproducibility from inexpensive starting materials, using simple techniques. Note, however, that the loss coefficients never got much below $0.1 \mathrm{~cm}^{-1}$, so a round trip through a $1 \mathrm{~cm}$ crystal would entail a loss of over $20 \%$. Virgin $\mathrm{ZnS}$ and $\mathrm{ZnSe}$ materials are prized for their extremely - high transparency and low absorption, even out to wavelengths as long as $10.6 \mu \mathrm{m}$, so there is something associated with $\mathrm{Cr}$ - doping that causes loss to appear. Loss reduction remains an ongoing topic of investigation.

\section{B. Long-wavelength diode arrays}

We built and tested two different diode arrays during the project. Both were based on long-wavelength (InGaAsP/InP) diode wafers obtained from Epitaxial Products, Inc. The wafers were sectioned into individual emitters and assembled into diode bars, which were then microlensed and combined into arrays. Since the TV camera used for microlensing the "standard" (800 - $900 \mathrm{~nm}$ ) bars did not detect the long-wavelength light, we set up a special ground-glass viewing screen and mid-IR camera for the new diode bars. Microlensing these bars turned out to be more difficult. Our first array had 4 bars and worked at $1650 \mathrm{~nm}$; the second had 10 bars and generated light at $1725-1750 \mathrm{~nm}$. The first (4-bar, $1650 \mathrm{~nm}$ ) diode array, when operated at a low duty cycle with a $50 \mu \mathrm{sec}$ pulsewidth, gave the slope data shown in the lower curve of Figure 3. A maximum diode power of $75 \mathrm{~W}$ was obtained at a drive current of $100 \mathrm{amp}$, and an array-integrated slope of $0.795 \mathrm{~W} / \mathrm{A}$, corresponding to a slope for each diode bar of $\sim 0.2 \mathrm{~W} / \mathrm{A}$. The performance of the second (10-bar, $1725 \mathrm{~nm}$ ) array was even more impressive-as evident in the upper curve of Figure 3, its output exceeded 200 Watts peak. The array's slope of $2.36 \mathrm{Watt} / \mathrm{Amp}$ corresponds to an average slope per bar of $\sim 0.24 \mathrm{Watt} / \mathrm{Amp}$. Although this is quite far below the $800-900 \mathrm{~nm}$ diode bar performance of $\sim 0.8$ Watt/Amp, it is still very good for this wavelength region. 


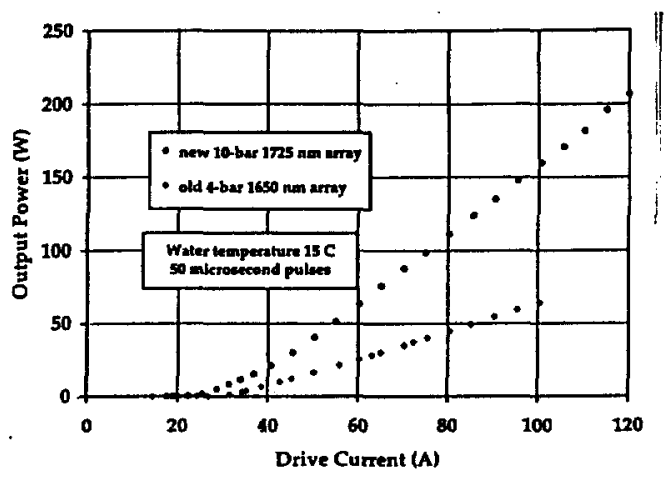

Fig. 3. Slope plots for two diode arrays used to pump $\mathrm{ZnSe}: \mathrm{Cr}^{2+}$ lasers.

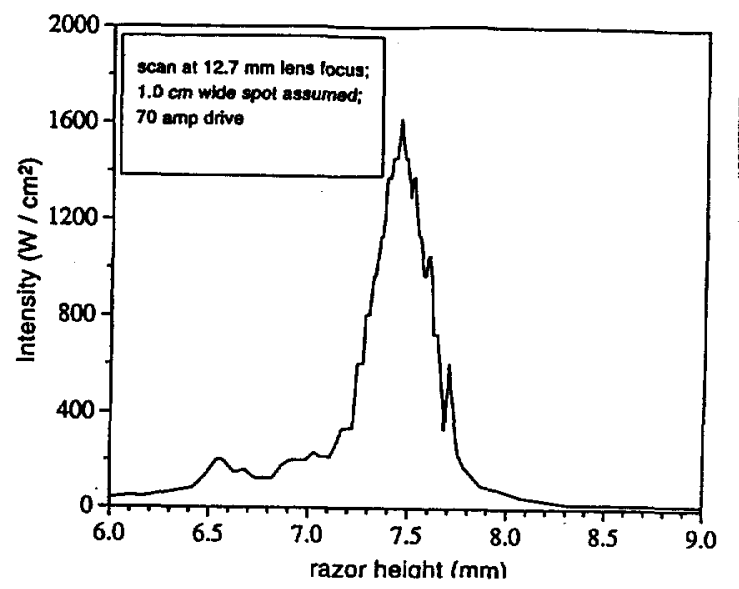

Fig.4. Intensity distribution of the 10-bar, 1725 -nm array at the focus of a $12.7 \mathrm{~mm}$ lens.

A razor scan of the the focused spot of the 10-bar array is shown in Figure 4, with the array driven at $70 \mathrm{Amp}$ (100 Watt peak output.) A gaussian width parameter of 280 $\mu \mathrm{m}$ is derived from a fit to this data. Because of mis-aiming of some microlensed bars, not all of the stripes overlapped in the focal region, putting some light in the wings of the distribution. In spite of that, the peak intensity of $1.6 \mathrm{~kW} / \mathrm{cm}^{2}$ is appreciable with respect to the $\mathrm{ZnSe}: \mathrm{Cr}^{2+}$ pump saturation intensity of $14 \mathrm{~kW} / \mathrm{cm}^{2}$. Pulsing the diodes at higher current significantly increases the focal intensity. Improvements in microlensing can probably double the intensity, with no increase in the heat delivered to the $\mathrm{ZnSe}: \mathrm{Cr}$ brick, leading to diode-pumped laser performance improvements.

The long-wavelength InGaAsP/InP diodes are likely to have applications beyond pumping $\mathrm{ZnSe}: \mathrm{Cr}^{2+}$ lasers. $\mathrm{CW}$ operation may be of interest, and to investigate the $\mathrm{CW}$ capability, a test was run on a single bar. It was feared that reliability would be low, but as Figure 5 shows, the output was very steady at 5 Watts for the first 100 hours (at 54 Amp drive current,) then at 8 Watts for the next 700 hours (at 75 Amp drive.) This was a surprise, especially considering that the bar was designed to have a high "fill factor" (small space between emitters,) allowing enough cooling for pulsed, but not $\mathrm{CW}$ operation. The implications are that a 10-bar array would deliver 80 Watts $\mathrm{CW}$, and that given good thermal management of a $\mathrm{ZnSe}: \mathrm{Cr}^{2+}$ laser, it too could run $\mathrm{CW}$. All in all, the diode array development program was very successful.

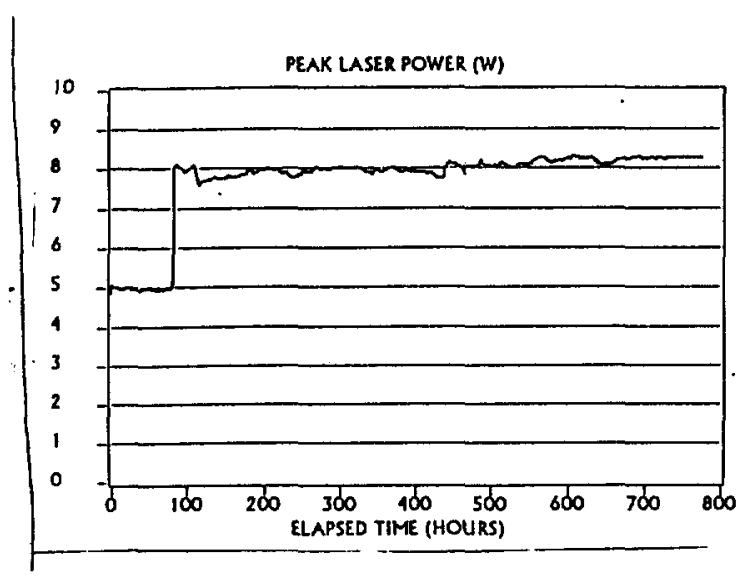

Fig. 5. Results of $\mathrm{CW}$ operation of a single 1725 -nm diode bar, at 54 Amp drive for 100 hours, then at $75 \mathrm{Amp}$ for 700 hours. 


\section{Saturable absorber}

Our work on the semiconductor-saturable-absorber passive $Q$ switch positioned us for the growth and testing of MQW structures, and exposed us to some pitfalls. One stumbling block was the lack of transparent InP substrates. Doped substrates (as one would use for producing diode lasers) exhibit quasi-free-carrier absorption that causes serious IR attenuation. Even in thin samples, this renders them virtually opaque to the $\mathrm{ZnSe}: \mathrm{Cr}^{2+}$ laser, and not suitable for intracavity use. An IR transmission spectrum of an undoped InP wafer (suitable for our purposes) is shown in Figure 6(a). The high refractive index $(\sim 3.2)$ of this material causes significant normal-incidence Fresnel losses, as expected. Insertion of this wafer at a steep angle into the cavity of an operating $\mathrm{ZnSe}: \mathrm{Cr}^{2+}$ laser reduced its output power somewhat, but did not quench lasing. A trial growth of a single quantum well (SQW) $\sim 70 \AA$ thick sandwiched between severalmicron thick InGaAs barrier layers resulted in a structure whose transmission spectrum is shown in Figure 6(b). The new features in the spectrum can be attributed to the InGaAs layers; the SQW is so thin as not to affect the spectrum noticeably. The $\sim 2200 \mathrm{~nm}$ target bandgap of the layers is evident as a steep rise in transmittance at that very wavelength. Our ability to tailor the bandgap validates the calibration of the MOCVD growth apparatus and methods. Transmission ripples in the $2200^{+} \mathrm{nm}$ region are due to ètalon effects in the InGaAs layers; the free-spectral range is evidently $\sim 100 \mathrm{~cm}^{-1}$. Opacity in the region below $2000 \mathrm{~nm}$ is consistent with an above-bandgap absorption coefficient on the order of $10^{4} \mathrm{~cm}^{-1}$. Laser performance testing of a similar structure could occur in a straightforward manner if the single quantum well were replaced with a series of many (say, up to $\sim 50$ ) quantum wells.
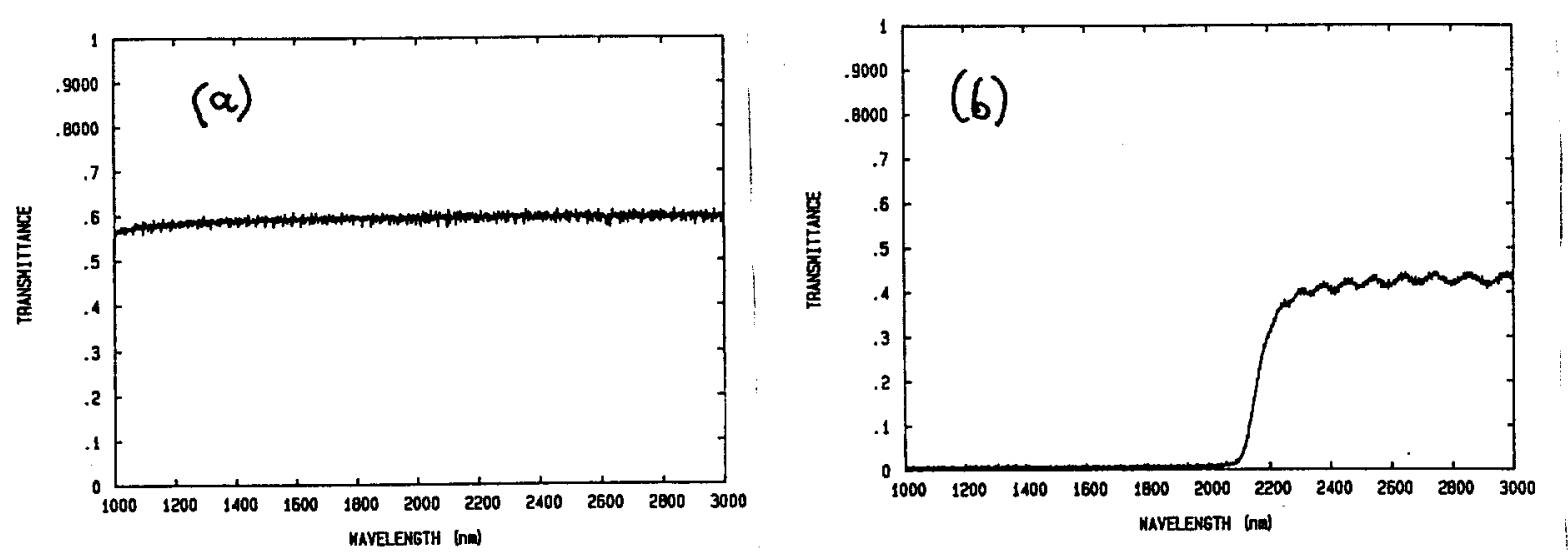

Fig. 6. Transmission spectra of undoped InP wafers (a) before and (b) after deposition of a single-quantum-well (SQW)/barrier-layer sandwich.

\section{D. $\mathrm{ZnSe}: \mathrm{Cr}$ laser results}

One of our goals was to demonstrate wide tunability of a $\mathrm{ZnSe}: \mathrm{Cr}^{2+}$ laser. Although we had done some tuning experiments with a birefringent tuner, we realized that a diffraction grating would provide simpler tuning and wider spectral coverage. The laser's gain was sufficient to overcome the additional loss introduced by a grating. Grating-tuning experiments were done by replacing the cavity high-reflector with a 420 line/mm diffraction grating on a rotation stage, and using curved output couplers. The diode array was removed and a pump beam from a $\mathrm{MgF}_{2}: \mathrm{Co}^{2+}$ laser was focused onto 
the crystal using the same cylindrical lens. Since the $\mathrm{MgF}_{2}: \mathrm{Co}^{2+}$ laser has a lowdivergence beam, its brightness is much higher than that of the diode array, making it easier to reach threshold with a lossy cavity element (i.e. grating.) Output wavelengths were checked with a monochromator. According to the tuning curve in Figure 7, the long-wavelength limit of operation appears to be $\sim 2670 \mathrm{~nm}$, but in fact the $\mathrm{OH}$ - induced absorption in the BK - 7 mirror substrate blocked the laser output, which actually extended to $2799 \mathrm{~nm}$. The short-wavelength cutoff was $2134 \mathrm{~nm}$; even though the emission cross section remains substantial, self-absorption most likely inhibits laser operation. Higher-power pumping of this laser may well extend the tuning range at both the long- and short - wavelength ends. With the laser running at $\sim 2600 \mathrm{~nm}$, we measured its linewidth at less than $1 \mathrm{~nm}$. Such a resolution is adequate for various condensedmatter studies, including sublimation of solid hydrogen in ICF target capsules.

Considering that there was no beam expander to increase the number of illuminated grating grooves, and no additional line-narrowing elements (e.g. ètalons), the laser should ultimately be capable of very-high-resolution operation, making it suitable for IR spectroscopy and remote sensing. The demonstrated wide spectral coverage (out to almost $2800 \mathrm{~nm}$ ) represents a validation of our claims regarding the tunability.

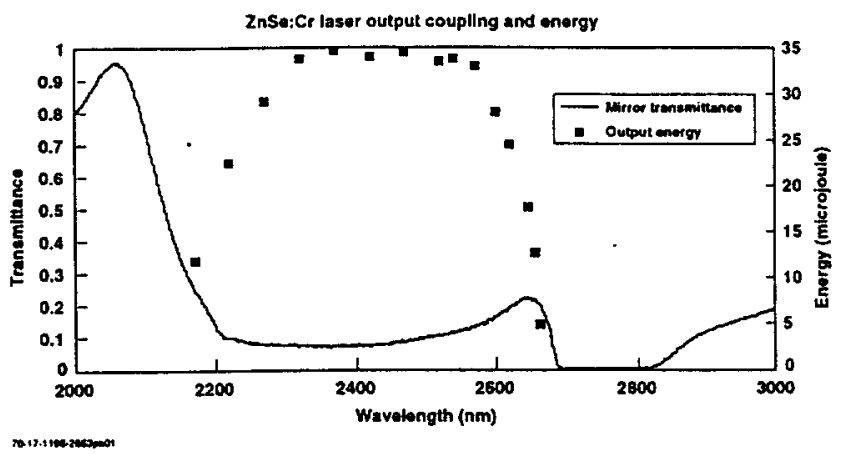

Fig. 7. Tuning characteristics obtained with $\mathrm{MgF} 2: \mathrm{Co}^{2+}$ laser pumping of $\mathrm{ZnSe}: \mathrm{Cr}$, resonated with a diffraction grating. The output - coupler transmittance spectrum reveals the $\mathrm{OH}$ absorption in the $\mathrm{BK}-7$ glass substrate material that blocked the laser's output from $\sim 2650-2800 \mathrm{~nm}$.

We have performed some experiments to test the power output with diode pumping. Under short-pulse $(50 \mu \mathrm{sec})$ conditions, with a low duty cycle, we obtained the data in Figure 8 . Using crystal $\# 690\left(\alpha_{\text {peak }}=6.3 \mathrm{~cm}^{-1} ; \alpha_{\text {loss }}=0.13 \mathrm{~cm}^{-1}\right)$ in a nearconfocal cavity with $10-\mathrm{cm}$ mirrors, and a series of 3 different output couplers, we found that the $85 \%$ reflector gave the highest output, at slightly over 3 Watts peak. This corresponds to an absolute optical-to-optical efficiency of $2 \%$ and an optical-to-optical slope efficiency of $3 \%$. (Figures given are $\mathrm{ZnSe}: \mathrm{Cr}^{2+}$ output with respect to diode-array output.) The low efficiencies can be blamed largely on the poor mode overlap between the pump volume and the resonated wave; in fact, much of the pump light would pass all the way through a crystal $1 \mathrm{~mm}$ thick! Our experiments done with end-pumping using a $\mathrm{MgF}_{2}: \mathrm{Co}^{2+}$ laser have shown that slope efficiencies over $25-30 \%$ (with respect to absorbed pump energy) can be obtained when the mode-matching is good. 


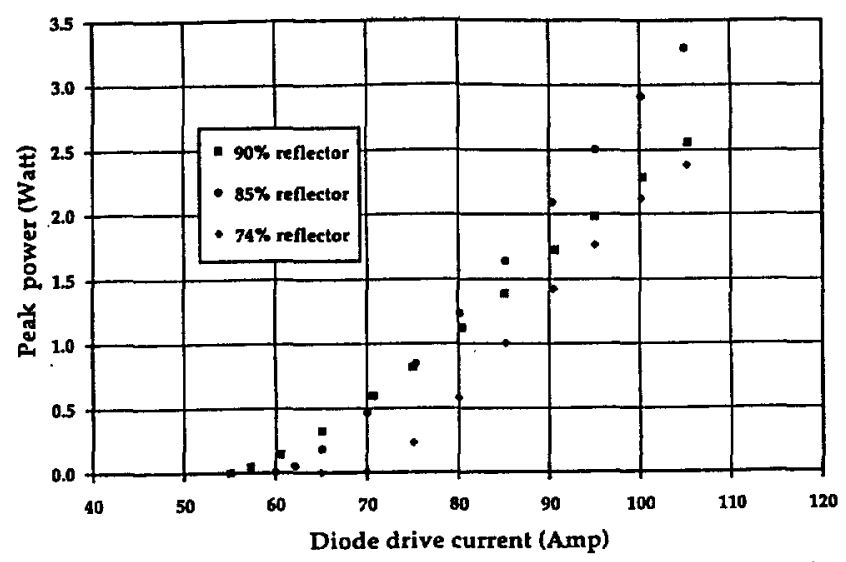

Fig. 8. Peak output power vs. diode-array drive current in a near-confocal resonator with three different output couplers, and crystal \#690.
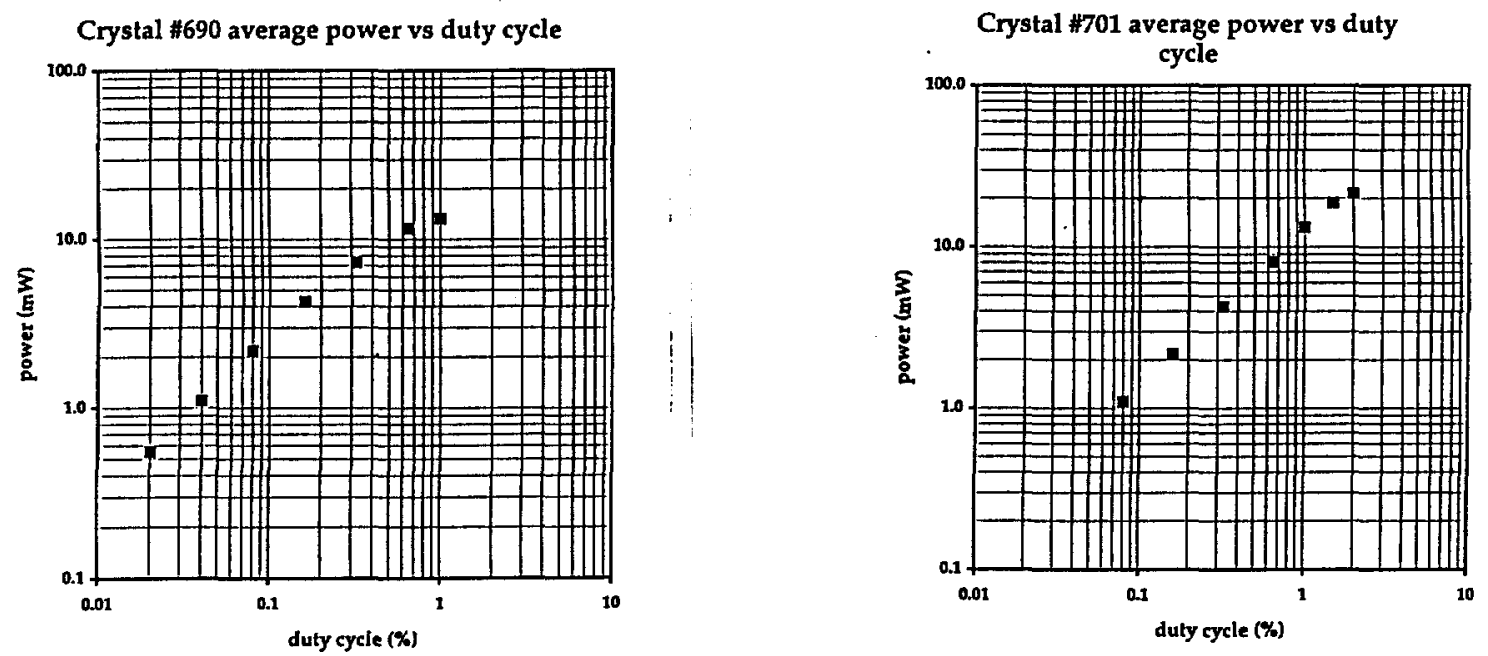

Fig. 9. Average power vs. duty cycle for crystals \#690 and \#701.

Average-power test results are shown in Figure 9. The diode-pumped laser was run with $50 \mu \mathrm{sec}$ pump pulses whose repetition rate was increased to raise the duty cycle. For example, $200 \mathrm{~Hz}$ operation corresponds to a pump duty cycle of $1 \%$. During the experiments, the duty cycle was increased until "rollover" was encountered. In Figure 9(a), crystal \#690 was again tested, and in the low-duty-cycle portion of the plot, the peak power of $\sim 3 \mathrm{~W}$ was maintained. At a $1 \%$ duty cycle, the power had fallen from the expected $30 \mathrm{~mW}$, to a value $\sim 15 \mathrm{~mW}$. A similar experiment using a "worse" crystal (\#701; $\alpha_{\text {peak }}=4.2 \mathrm{~cm}^{-1} ; \alpha_{\text {oss }}=0.22 \mathrm{~cm}^{-1}$; lower doping, and higher loss) showed that at low duty cycle, the power was lower, but that the rollover did not occur until a duty cycle $-2 \%$. This allowed the laser to produce a higher average output power over $20 \mathrm{~mW}$. Our interpretation of these results is that the heat load on the crystal ( $\sim 2 \mathrm{~W}$ at $1 \%$ duty cycle) is high enough to cause thermal lensing that destabilizes the laser cavity. Even if the gain per pass at low drive is reduced, a lower-doped crystal experiences a smaller temperature gradient in the gain region, mitigating thermal lensing. $\mathrm{ZnSe}$, being a semiconductor whose band gap declines with increasing temperature, exhibits a comparitively-large value of $\mathrm{dn} / \mathrm{dT} \sim 7 \times 10^{-5} \mathrm{~K}^{-1}$. In spite of the high thermal conductivity of $\mathrm{ZnSe}(0.17$ $\mathrm{W} / \mathrm{cm}-\mathrm{K}$,) the thermal-lens focal length (in the vertical axis) is estimated at only a few $\mathrm{cm}$ 
when $2 \mathrm{~W}$ pump power is absorbed. Horizontal-axis focusing is much less severe in the side-pumped geometry employed to date. Use of a shorter cavity (than the $5-10 \mathrm{~cm}$ lengths tried to date) may well allow operation at higher duty factor and higher output power. Typical crystal lengths of $\sim 1 \mathrm{~cm}$ do allow for cavity shortening. However, realization of the full average-power potential of $\mathrm{ZnSe}: \mathrm{Cr}^{2+}$ lasers mandates another look at the cavity configuration. Perhaps a monolithic, end-pumped design, a waveguide, or an "active mirror" configuration will cope better with thermal lensing.

\section{Discussion}

Wide tunability and diode-pumped operation of $\mathrm{ZnSe}: \mathrm{Cr}^{2+}$ lasers have been well demonstrated in out laboratory. There is still important work to do in the quest for higher average power. New resonator designs that mitigate thermal lensing and provide good "mode fill" will be needed. CW lasing and ultra-short-pulse generation are potential operating regimes we have not reached yet, but they will probably be demonstrated within a year or two, likely by our colleagues in other laboratories.

Interest in $\mathrm{Cr}^{2+}$ lasers in other parts of the solid-state-laser community has been high, and there have been spectroscopic studies of $\mathrm{Cr}^{2+}$-doped $\mathrm{CdSe}$ and $\mathrm{CdMnTe}$, and laser experiments reported on $\mathrm{CdMnTe}: \mathrm{Cr}^{2+}$.[4] Transition-metal-doped zinc chalcogenides can also function as saturable absorbers ( $Q$ switches.) Collaborations between LLNL and various groups worldwide have begun, for the purposes of producing $\mathrm{Cr}^{2+}$-doped samples and exploring some of the desirable properties of the new laser materials. Crystal-growth companies (e.g. Cleveland Crystals) are now selling $\mathrm{Cr}^{2+}$ doped material on a custom basis. So, with time, we should be seeing all kinds of interesting progress in mid-IR solid-state lasers, as a result of the original work done at LLNL.

\section{Bibliography}

In the course of the projects, we published several refereed papers and obtained a patent; a list follows. We also gave numerous conference presentations, some invited.

1. "Transition metal-doped zinc chalcogenides: spectroscopy and laser demonstration of a new class of gain media," Laura D. DeLoach, Ralph H. Page, Gary D. Wilke, Stephen A. Payne, and William F. Krupke, IEEE J. Quantum Electron. 32, 885 - 895 (1996.)

2. " $\mathrm{Cr}^{2+}$ - doped zinc chalcogenides as efficient, widely-tunable mid-infrared lasers," Ralph H. Page, Kathleen I. Schaffers, Laura D. DeLoach, Gary D. Wilke, Falgun D. Patel, John B. Tassano, Stephen A. Payne, William F. Krupke, K.-T. Chen, and Arnold Burger, IEEE J. Quantum Electron. 33, 609 - 619 (1997.)

3. "High-power operation of InGaAsP - InP laser diode array at $1.73 \mu \mathrm{m}, " \mathrm{~J}$. A. Skidmore, B. L. Freitas, C. E. Reinhardt, E. J. Utterback, R. H. Page, and M. E. Emanuel, Photon Tech. Lett. 9, 1334 - 1336 (1997.)

4. Wm F. Krupke, Ralph H. Page, Laura D. DeLoach, and Stephen A. Payne, "Transition-Metal Doped Sulfide, Selenide, and Telluride laser crystal and lasers," U.S. patent 5,541,948 (1996). 


\section{Acknowledgements}

Many people have contributed to the success of our $\mathrm{ZnSe}: \mathrm{Cr}^{2+}$ laser projects. Bill Krupke and Steve Payne initiated our program; Laura DeLoach and Gary Wilke participated in the first spectroscopic and laser experiments; Prof. Arnold Burger taught us about diffusion-doping; Kathleen Schaffers and John Tassano have done numerous diffusion-doping growth runs; Jay Skidmore, Mark Emanuel, Barry Freitas, Victor Sperry, Everett Utterback, Larain Di Mercurio, Cathy Reinhardt, and Joe Satariano have produced the long-wavelength diode arrays and saturable absorbers; John Lang has produced a variety of machined parts; Falgun Patel, Randy Bartels, and Phil Waide have helped with laser experiments; Ron Vallene and Peter Thelin have taken care of cutting and polishing crystals; Ray Beach spearheaded the laser design and modeling; and Howard Powell has provided moral support.

\section{$\underline{\text { References }}$}

[1] J. E. Bernard and A. J. Alcock, "High-efficiency diode-pumped Nd:YVO 4 slab laser," Opt. Lett. 18, 968 - 970 (1993).

[2] J. A. C. Terry and M. J. P. Payne, "Passive Q-switching of infrared lasers with multiple quantum well structures," J. Phys. D: Appl. Phys. 28, 2015 - 2019 (1995.)

[3] A. E. Siegman, Lasers (University Science Books, Mill Valley, California: 1986), pg. 1028.

[4] U. Hömmerich, X. Wu, V. R. Davis, S. B. Trivedi, K. Grasza, R. J. Chen, and S. Kutcher, "Demonstration of room-temperature laser action at $2.5 \mu \mathrm{m}$ from $\mathrm{Cr}^{2+}: \mathrm{Cd}_{0.85} \mathrm{Mn}_{0.15} \mathrm{Te}$," Optics Lett. 22, 1180 - 1182 (1997.) 


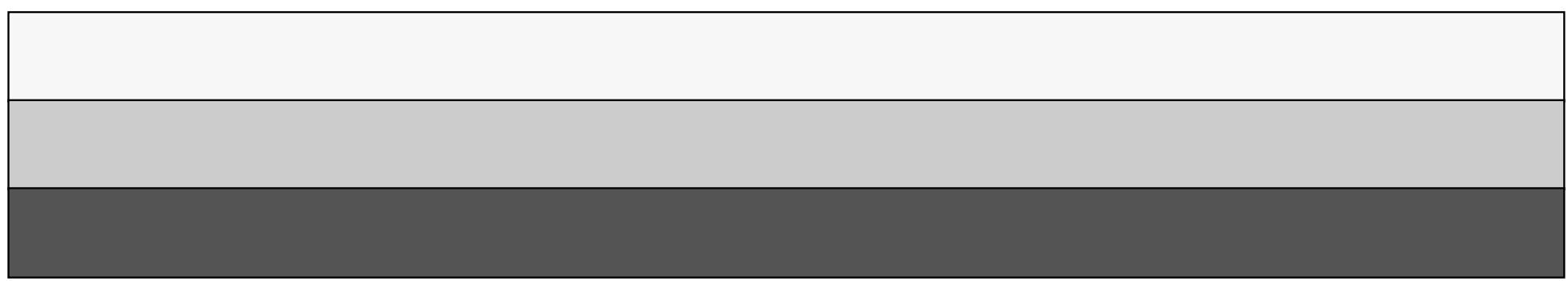

